\title{
Levels of toxic and essential metals in maternal cord blood and anthropometry at birth: a pilot study
}

\author{
Benjamin Oritsemuelebi', Chiara Frazzoli², Eze Chidi Eze ${ }^{3}$, Cajetan Elochukwu Ilo ${ }^{3}$, Ify L. Nwaogazie ${ }^{4}$, Orish Ebere \\ Orisakwe $^{5}$ - \\ 1 Department of Experimental Pharmacology \& Toxicology, Faculty of Pharmacy, University of Port Harcourt, Rivers State, Nigeria, ${ }^{2}$ Department for \\ Cardiovascular and Endocrine-Metabolic Diseases and Ageing, Istituto Superiore di Sanità, Rome, Italy, ${ }^{3}$ Department of Pharmacology, College of \\ Health Sciences, Nnamdi Azikiwe University, NnewiCampus, Nnewi, Nigeria, ${ }^{4}$ African Centre of Excellence for Oilfield Chemicals Research (ACE- \\ CEFOR), University of Port Harcourt, PMB, Port Harcourt, Nigeria, 5 Department of Experimental Pharmacology \& Toxicology, Faculty of Pharmacy, \\ University of Port Harcourt, Rivers State, Nigeria; African Centre of Excellence for Public Health and Toxicological Research (ACE-PUTOR), University of \\ Port Harcourt, Port Harcourt, Nigeria \\ Keywords: cord blood, heavy metals, anthropometric parameters, maternal blood, prevention \\ https://doi.org/10.29392/001c.29888
}

\section{Journal of Global Health Reports}

Vol. 5, 2021

\begin{abstract}
Background
Anthropometric parameters at birth are important indicators of child vulnerability to the risk of childhood illness, and consequently, the chance of survival and risk of diseases late in life. The aim of this study was to investigate correlations between toxic (aluminium, antimony, arsenic, cadmium, lead and mercury) and essential metals (copper, manganese, selenium and zinc) in maternal and umbilical cord blood samples, with newborn anthropometric parameters in a predominantly agricultural community of Ebony State, Nigeria.
\end{abstract}

\begin{abstract}
Methods
Questionnaires were administered to 60 pregnant women at the Federal Teaching Hospital in Abakaliki, South-East Nigeria, to collect demographic information and lifestyle during pregnancy. In addition, we measured several anthropological parameters of newborns, including head circumference, birth weight and birth length. Furthermore, cord and maternal blood samples were analysed by the Inductively Coupled Plasma Mass Spectrometry (ICP-MS).
\end{abstract}

\section{Results}

Most metals had a strong correlation between maternal and cord blood. Maternal characteristics like sleeping pattern, gestation age at delivery and maternal weight significantly predicted $76 \%$ variations in baby weight. Maternal blood aluminium was inversely correlated with body weight $(r=-0.61)$ and birth length $(r=-0.61)$. Gestation age at delivery, maternal weight and baby weight were strong predictors of the baby length. Toxic metals were associated with altered anthropometric parameters at birth, with varying contributions to the altered anthropometric outcomes.

\section{Conclusions}

Besides the negative effect of toxic metals on newborn anthropometry, we also detected interesting interactions between metals; maternal exposure to lead negatively correlates with manganese and zinc in the cord blood, while maternal exposure to aluminium was positively correlated with copper. These results contribute to the broader understanding of the environmental effects on maternal and child health.

Nigeria has the largest number of global under-five deaths, and almost half of these occur in the newborn period. ${ }^{1}$ Birth weight is the main indicator of health outcomes, especially the short-term survival of the newborn. Size at birth may reflect urgent attention because of the significantly increased risk it poses for infants and young children and the risk of developing chronic diseases in adulthood. ${ }^{2}$ Prenatal and early childhood periods are particularly susceptible to nutrient deficiencies and toxicity of trace elements due to the episodes of rapid growth, relatively low mineral stores at birth, poor intestinal absorption, excess intestinal and renal losses, high vulnerability to oxidative stress, high exposure to a bodyweight, immature metabolic pathways, delicate developmental processes, and numerous life-course effects. ${ }^{3,4}$ An oxidant/antioxidant imbalance in infants is implicated in the pathogenesis of the major com- 
plications of prematurity, including respiratory distress syndrome (RDS), necrotizing enterocolitis (NEC), chronic lung disease (CLD), retinopathy of prematurity (ROP) and intraventricular haemorrhage (IVH). ${ }^{5}$ Since foetal development depends on genetics, maternal nutrition, and placental circulation, 6 environmental and lifestyle modifications over time could have affected our risk of diseases and its overall burden. The environment is continuously and increasingly exposed to heavy metals from anthropogenic sources. In Nigeria, anthropogenic sources of heavy metals include artisanal mining, illegal refining, inadequate disposal of waste, sewage sludge, smelting operations, industrial production and use, domestic and agricultural use of metals and metal-containing compounds, vehicle traffic, the burning of fossil fuels for heating and cooking, construction sites and various industries. ${ }^{7,8}$ Adverse outcomes in pregnancy, such as foetal loss, retarded foetal growth, congenital anomalies and impaired neurodevelopment, are associated with prenatal Lead and Mercury exposure. ${ }^{9} \mathrm{Al}-$ though the placenta has been reported to be a partial barrier for cadmium, some studies have presented the harmful health effects of prenatal cadmium exposure. ${ }^{8,10}$ Many have tried to establish epidemiological relationships between these exposures and alterations in foetal development and to push the need for improved biomarkers of trace element status. ${ }^{11-13}$ Hitherto, few studies that have evaluated the influence of potential toxic metal on birth outcome in Nigeria have focussed mainly on highly industrialised areas. This study aimed to evaluate the levels of toxic and essential metals in maternal and cord blood and their effects on anthropometric parameters of newborn in a non-industrialised, predominantly agricultural community Abakaliki, Nigeria. To the best of our knowledge, only a few studies on heavy metal levels in Nigerian mother-child pairs, including umbilical cord blood sampling, have been published so far.

\section{METHODS}

\section{INVESTIGATION AREA}

Abakaliki is the capital of Ebony state, South Eastern Nigeria. It lies at the intersection of roads from Enugu, Afikpo, and Ogoja. An agricultural trade centre (yams, cassava, $\underline{\text { rice}}$, and palm oil and kernels), the town is located in an area known for its Lead, Zinc, and limestone deposits.

\section{RECRUITMENT AND DATA COLLECTION}

The study population was 60 pregnant women from the Federal Teaching Hospital in Abakaliki, who agreed to participate in the study. The eligibility criteria to participate in the present study were as follows: living in the study area Abakaliki for at least five years; aged 18 to 40 years and no report of diabetes, hypertension, or preeclampsia. Women were recruited at the 3rd trimester of pregnancy and followed up until delivery. Pregnant women were briefly screened for eligibility, recruited, enrolled, consented (before delivery), and interviewed after delivery by bilingual interviewers in their preferred or native language (English, Igbo) using a standardized questionnaire to collect general information on bio-demographic characteristics (e.g. age, menarche, height), family history of hypertension or dia- betes, and lifestyle (e.g. smoking and passive smoking, alcoholic drinking) during pregnancy, and obstetric data. In addition, details on the mother's family records, including some congenital diseases or prior miscarriages, stillbirth, weight at delivery, birth date, gender, gestation week and birth weight, were obtained from the medical delivery record.

\section{QUESTIONNAIRE}

The robust validity of the questionnaire "Levels of toxic and essential metals in maternal and cord blood and their effects on anthropometric parameters of newborns from Abakaliki, Nigeria" was verified by the experts in Measurement and Evaluation School of public health at the University of Port Harcourt. The questionnaire was administered to them for scrutiny, and their recommendations were affected before they were administered.

\section{MATERNAL AND CORD BLOOD COLLECTION AND PRE- TREATMENT}

From January 2019 to July 2019, some midwives under a physician's supervision obtained maternal and cord blood using a standard aseptic technique. Approval for this study was granted by Federal Medical Centre Abakaliki, Ebonyi State Nigeria Health Research Ethics Committee (REC APPROVAL NUMBER 11/07/2018 - 14/09/2018). Maternal blood $(2 \mathrm{ml})$ was extracted via venepuncture using metalfree syringes into a trace metal-free cryovial containing ethylenediaminetetraacetic acid (EDTA) as an anticoagulant at Federal Medical Centre Abakaliki, Ebony State Nigeria, while $2 \mathrm{ml}$ of umbilical blood was collected from the cord using needle and syringe into a trace metal-free cryovial containing ethylenediaminetetraacetic acid (EDTA) as an anticoagulant also. Blood samples were taken for laboratory analysis and then frozen to $-80^{\circ} \mathrm{C}$ and transported using a cold blood chain to Laboratory called Lighthouse Petroleum Engineering LTD at No 6, Lighthouse Road, GRA Effurun Delta State, Nigeria. Prior to analysis, $2 \mu$ of blood samples were digested with $1 \mu$ of concentrated nitric acid (70\% nitric acid; Optima grade, Fisher Scientific) overnight at room temperature. The following morning, $2 \mu$ l hydrogen peroxide (30\% Suprapur grade, Sigma-Aldrich) was added to each digest and allowed to sit overnight at room temperature, stored in the refrigerator until analysis.

\section{LABORATORY METHODS}

The dilution and handling of the samples were done following the ultra-clean lab procedure developed for water samples with very low lead levels. ${ }^{14}$ All lab equipment that came into contact with the sample, in particular, was thoroughly decontaminated. An Agilent 7500c series Inductively Coupled Plasma Mass Spectrometer (ICP-MS) with a collision cell was used to determine the metal content of each sample. The manufacturers' suggested instrument operating conditions were used. Blood samples were mixed with the chemical cocktail in the sample tubes and pumped directly into the instrument. A reagent blank (diluent without blood), a duplicate sample, and a normal reference 
Table 1. Skewness for metal concentration in mother and baby cord.

\begin{tabular}{ccc}
\hline Heavy Metals & Baby Cord & Mother \\
\hline Cadmium & 0.031 & -0.280 \\
Manganese & -0.033 & -0.327 \\
Antimony & 0.000 & 0.000 \\
Selenium & 0.000 & 0.000 \\
Zinc & 0.313 & 1.002 \\
Mercury & 0.000 & 0.000 \\
Aluminium & 0.597 & 0.513 \\
Copper & 1.356 & -0.480 \\
Arsenic & 0.000 & 0.000 \\
Lead & 0.000 & 1.197 \\
\hline
\end{tabular}

Number of observations $=60$

blood sample (NIST) 1640 combined with the diluents were used with each batch of blood samples tested. The process detection limit was $0.2 \mu \mathrm{g} / \mathrm{dl}$, measured as three times the standard deviation for the reagent blanks.

\section{MEASUREMENT OF ANTHROPOMETRIC PARAMETERS}

Anthropometric variables (head circumference, abdominal circumference, birth weight, birth length) of the newborns were measured. Low birth weight was defined as birth weights (<2500 g). ${ }^{13}$

\section{STATISTICAL ANALYSIS}

The data were statistically analysed using statistical SPSS package (23.0) version (SPSS Inc, USA). The normality of each variable's distribution was verified; descriptive analysis was carried out while multiple comparisons were made using Pearson's correlation. Principal Component Analysis (PCA) was first carried out as a factor reduction technique. Given a relationship between one dependent variable and multiples of independent variables, PCA attempts to identify the most sensitive independent variables, often called principal components, are employed in multiple regression modelling, and the less sensitive variables are discarded. This is economical when sourcing input data to simulate for prediction purposes. The principal components are usually showcased in bold prints after varimax rotation using XLSTAT 2016 software with an inbuilt option called Principal Component Regression (PCA) to develop the regression models. ${ }^{15}$

\section{RESULTS}

\subsection{CHECK FOR NORMALITY IN HEAVY METAL CONCENTRATION IN MOTHER BLOOD AND BABY CORD}

The skewness for the heavy metal concentration in the maternal blood and baby cord was computed, and the result is presented in Table 1. The result showed that most of the heavy metals concentration in both the mother blood and baby cord had some form of skewness (negative or positive). It was observed that copper in the baby cord had the highest positive skewness while Lead metal in the mother blood equally had the highest positive skewness The $\mathrm{Q}-\mathrm{Q}$ plot, presented in Figure 1, showed clearly that most of the heavy metal concentrations in the maternal blood and baby cord did not fall on the $45^{\circ}$ diagonal line. The result from the QQ plot showed that the heavy metal concentration in both the mother blood and baby cord is not normally distributed. Thus, both the skewness and Q-Q plots complimented each other.

\subsection{HEAVY METAL CONCENTRATION IN MOTHER AND BABY CORD}

Higher metal concentrations were observed in the mother blood than in the baby cord blood (Table 2). Among all metals analysed, zinc was predominant in both the mother and baby cord blood, followed by copper; a very low concentration of antimony, arsenic, mercury and selenium was found in both the mother and baby cord. Figures $\underline{2}$ and $\underline{3}$ show the level of metals concentration in the mother and baby cord blood. Higher metals concentration were found in the mother blood than in the baby cord blood, this can be attributed to the fact that the pathway for the heavy metal to the baby is mainly through the mother.

The $\mathrm{z}$ - test was carried out to check if the difference seen in the metal's concentrations in the mother and baby cord blood were significant (Table 3a). The test showed that the concentrations of aluminium, cadmium, copper, manganese, and zinc found in the mother blood were significantly higher than those found in the baby cord (protective effect of the human placenta), while the concentrations of antimony, arsenic, lead, mercury and Selenium were not. Noticeably, the community seems deficient in selenium.

The mean zinc concentration in the mother blood was $0.879 \mu \mathrm{g} / \mathrm{l}$ while for the baby cord it was $0.639 \mu \mathrm{g} / \mathrm{l}$, the result showed that there was a $27 \%$ reduction in the amount of zinc transferred from the mother to the baby cord. The 
mean copper concentration in the mother blood was 0.783 $\mu \mathrm{g} / \mathrm{l}$ while in the baby cord was $0.513 \mu \mathrm{g} / \mathrm{l}$ which means a $35 \%$ reduction in the amount of copper transferred from the mother to the baby. As expected, cadmium had the highest reduction of metal transfer from maternal blood to the baby cord (Table $3 \mathrm{~b}$ ), with approximately $55 \%$ reduction. ${ }^{8}$

\section{BLAND AND ALTMAN AGREEMENT TEST}

The agreement in the concentration of heavy metals in the mother and baby cord were evaluated using the Bland and Altman analysis test and the result are presented in Figures 4 to 8 , while Table 3 c shows the bias in the heavy metals concentration in the baby cord and limit of agreement. Figure 4 which shows the agreement between the concentration of cadmium in the baby cord and mother blood showed that there was systematic bias in the concentration of cadmium in the baby cord, as all the individual differences between the cadmium concentration in baby cord and mother blood were lower than the difference of zero. The bias obtained for the cadmium concentration in the baby cord was -0.0168 (thick blue line), which indicated that on average that the difference in the cadmium concentration in the baby cord was $-0.0168 \mu \mathrm{g} / \mathrm{l}$ less than what was obtained in the mother blood. The confidence interval for the bias ranged from -0.0188 to -0.0148 (thin broken blue lines), does not include 0 which confirms that the there is no agreement between the cadmium concentration in the baby cord and mother blood and confirm that the cadmium concentration in the baby cord has lower concentration than what was obtained in the mother blood. The limit of agreement for the cadmium concentration ranged from -0.0319 to -0.0016 (thin broken red line). Similar observations were also noticed in manganese, zinc, aluminum and copper metals in the baby cord. All had systematic bias for metal concentration in the baby cord, as the individual differences were all less than zero. The bias recorded for manganese, zinc, aluminum and copper in the baby cord were -0.0184 , $-0.2417,-0.0146$ and -0.2703 respectively. The bias showed that the heavy metal concentrations in the baby cord were lower that what were obtained in the mother blood. The confidence interval of the bias for all the metals showed that they did not contain zero, which validated that the concentration of heavy metals in the baby cord did not agree with that of the mother blood.

\section{SECONDARY DEFICIENCIES}

In other to check the relationship between the metal level in the blood of the mother and the cord of the baby, Pearson correlation was used. The result is shown in the Table 4. While there was no strong linear relationship between similar metals concentration in the mother blood and the baby cord, good association was found between dissimilar metals in the mother blood and the cord blood. In particular:

1. the concentration of lead in the mother blood had good level of negative correlation with either Manganese and Zinc in the baby cord blood, which was significant at an alpha level of 0.05 . The higher the concentration of lead in the mother blood the lower that concentration of Manganese and Zinc in the baby
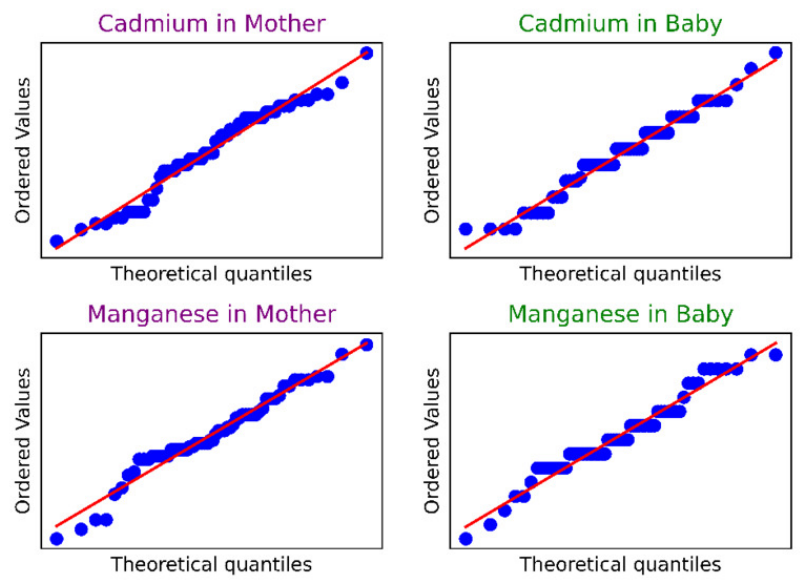

Zinc in Mother
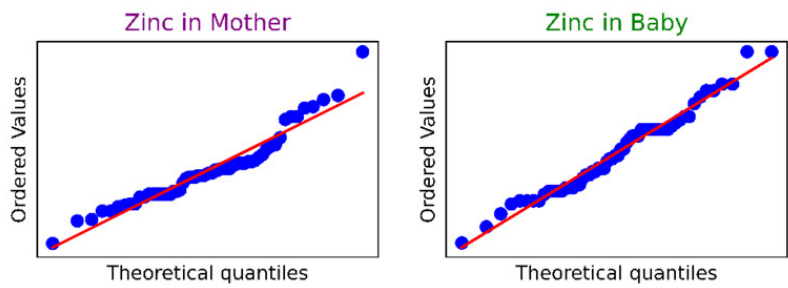

Aluminium in Mother
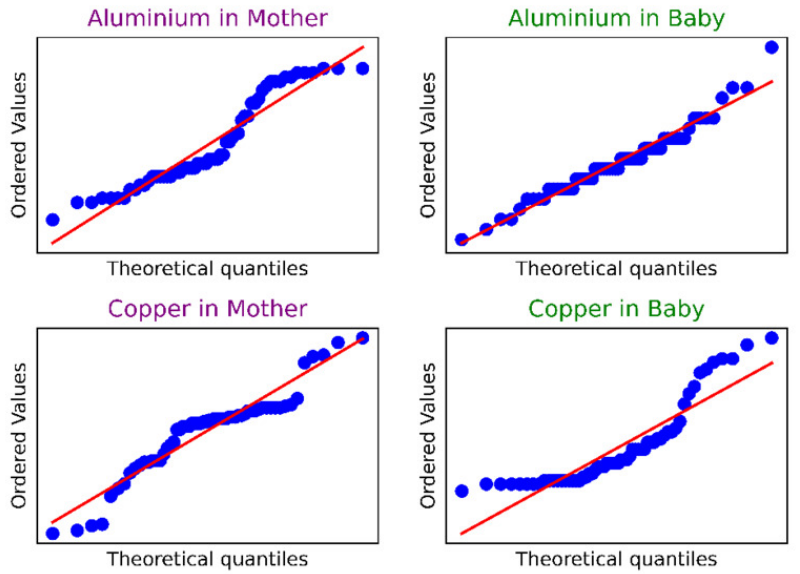

Lead in Mother

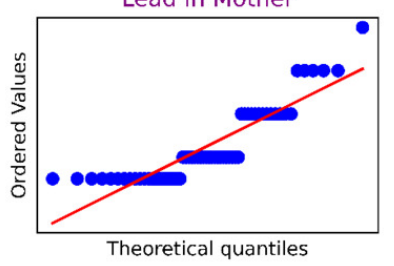

Lead in Baby

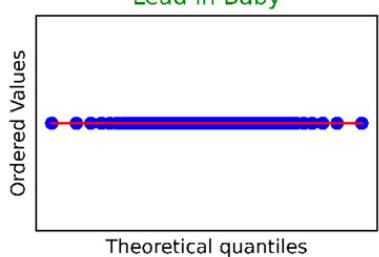

Figure 1. Q-Q plots of heavy metal concentrations in mother and baby cord.

cord blood.

2. the concentration of aluminium in the mother blood had good level of positive correlation with copper in the cord of the baby and it was significant at alpha level 0.05 . The higher the aluminium in the mother blood the higher the copper in the baby cord blood.

\section{TOXIC EXPOSURE AND NEWBORN BODY SIZE}

The relationship between the baby body size and the heavy metals in the mother blood is shown in Table 5. Aluminium in the mother had the strongest correlation with the baby weight and baby length. The higher the concentration of 
Table 2. Descriptive statistic of heavy metal in mother and baby cord.

\begin{tabular}{|c|c|c|c|c|c|}
\hline \multirow{2}{*}{ Metals } & \multirow{2}{*}{ Human } & \multicolumn{4}{|c|}{ Metal Concentration $(\mu \mathrm{g} / \mathrm{l})$} \\
\hline & & Mean & std & Min & Max \\
\hline \multirow{2}{*}{ Aluminium } & Baby Cord & 0.0166 & 0.0035 & 0.0090 & 0.0280 \\
\hline & Mother & 0.0313 & 0.0102 & 0.0140 & 0.0490 \\
\hline \multirow{2}{*}{ Antimony } & Baby Cord & 0.0010 & 0.0000 & 0.0010 & 0.0010 \\
\hline & Mother & 0.0010 & 0.0000 & 0.0010 & 0.0010 \\
\hline \multirow{2}{*}{ Arsenic } & Baby Cord & 0.0010 & 0.0000 & 0.0010 & 0.0010 \\
\hline & Mother & 0.0010 & 0.0000 & 0.0010 & 0.0010 \\
\hline \multirow{2}{*}{ Cadmium } & Baby Cord & 0.0127 & 0.0026 & 0.0080 & 0.0190 \\
\hline & Mother & 0.0295 & 0.0073 & 0.0140 & 0.0460 \\
\hline \multirow{2}{*}{ Copper } & Baby Cord & 0.5128 & 0.1161 & 0.3900 & 0.8300 \\
\hline & Mother & 0.7832 & 0.2658 & 0.1200 & 1.3800 \\
\hline \multirow{2}{*}{ Lead } & Baby Cord & 0.0100 & 0.0000 & 0.0100 & 0.0100 \\
\hline & Mother & 0.0126 & 0.0086 & 0.0050 & 0.0400 \\
\hline \multirow{2}{*}{ Manganese } & Baby Cord & 0.0473 & 0.0028 & 0.0400 & 0.0530 \\
\hline & Mother & 0.0658 & 0.0126 & 0.0330 & 0.0940 \\
\hline \multirow{2}{*}{ Mercury } & Baby Cord & 0.0010 & 0.0000 & 0.0010 & 0.0010 \\
\hline & Mother & 0.0010 & 0.0000 & 0.0010 & 0.0010 \\
\hline \multirow{2}{*}{ Selenium } & Baby Cord & 0.0010 & 0.0000 & 0.0010 & 0.0010 \\
\hline & Mother & 0.0010 & 0.0000 & 0.0010 & 0.0010 \\
\hline \multirow{2}{*}{ Zinc } & Baby Cord & 0.6387 & 0.1271 & 0.3600 & 0.9500 \\
\hline & Mother & 0.8793 & 0.2446 & 0.3600 & 1.7200 \\
\hline \multicolumn{6}{|c|}{$\begin{array}{l}\text { NB: Its only Lead }(\mathrm{Pb}) \text { that is expressed in ( } \mu \mathrm{g} / \mathrm{dl}) \text {, the original value of lead was was converted from }(\mu \mathrm{g} / \mathrm{l}) \text { to }(\mu \mathrm{g} / \mathrm{dl}) \text {, thus the value } \\
\text { below }\end{array}$} \\
\hline \multirow[b]{2}{*}{ Lead ( $\mu \mathrm{g} / \mathrm{dl})$} & Baby Cord & 0.00100 & 0.0000 & 0.00100 & 0.00100 \\
\hline & Mother & 0.00126 & 0.0086 & 0.00050 & 0.00400 \\
\hline
\end{tabular}

aluminium in the mother blood the smaller the weight of the baby and the length of the baby. This result showed that the level of Aluminium concentration in the mother blood should be monitored. There was no strong correlation relating the baby head circumference with heavy metals.

The selected variables in each component were used as independent variables while the baby weight, baby length and head circumference were used as dependent variables in developing regression models.

\section{PRINCIPAL COMPONENT ANALYSIS}

Principal component analysis was performed on the measured mother variables to obtain principal components used for independent variables in regression analysis. The principal axis method was used to extract the components, and this was followed by varimax (orthogonal) rotation to obtained uncorrelated components. The result of the Eigenvalue, which was used to retain the number of components, is presented in Table 6. Eigen-one criteria and cumulative proportion of variances were used in selecting the number of components that would be retained for varimax (orthogonal) rotation. From Table 6, six components had Eigenvalues greater than unity and the cumulative proportion of variance for the six components accounted for $72.44 \%$ of the total variance, which lead the choice in retaining six

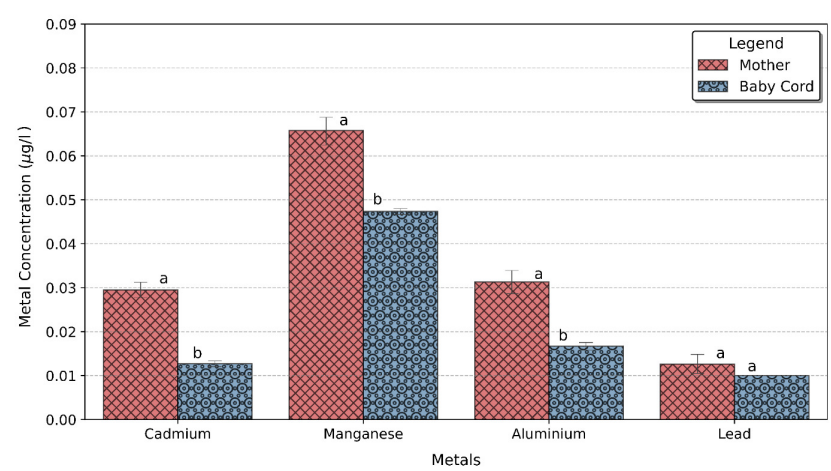

Figure 2. Heavy metals in the mother and baby cord.

components for varimax rotations.

\section{EIGEN VALUE}

The numbers of maternal variables that were retained on each of the component after varimax rotation is presented in Table 5 . The maternal variables are said to be loaded on a component if the factor loading score is greater than 0.4. From Table 5, maternal age, maternal weight, mother $\mathrm{BMI}$, and gestation weight gain were the maternal variables 
Table 3a. Test of significance in the metal concentrations in the mother and baby cord using z-test

\begin{tabular}{lcccccc}
\hline \multicolumn{1}{c}{ Metals } & Cadmium & Manganese & Zinc & Aluminium & Copper & Lead \\
\hline Difference & 0.0168 & 0.0184 & 0.2407 & 0.0146 & 0.2703 & 0.0026 \\
z (Observed value) & 16.8815 & 11.0799 & 6.7616 & 10.5199 & 7.2186 & 2.3669 \\
$|z|$ (Critical value) & 1.9600 & 1.9600 & 1.9600 & 1.9600 & 1.9600 & 1.9600 \\
p-value (Two tailed) & $<0.0001$ & $<0.0001$ & $<0.0001$ & $<0.0001$ & $<0.0001$ & 0.0179 \\
\hline
\end{tabular}

Level of significant $=5 \%$

Table 3b. Percentage reduction in metal concentration in mother blood and baby cord blood

\begin{tabular}{|c|c|c|c|c|c|c|c|}
\hline & Aluminium & Cadmium & Copper & Lead & Manganese & Selenium & Zinc \\
\hline Baby Cord & 0.017 & 0.013 & 0.513 & 0.010 & 0.047 & 0.001 & 0.639 \\
\hline Mother & 0.031 & 0.029 & 0.783 & 0.013 & 0.066 & 0.001 & 0.879 \\
\hline \% reduction & 45 & 55 & 35 & 23 & 29 & 0 & 27 \\
\hline
\end{tabular}

that loaded strongly on component 1 . For component 2 , gestation age at delivery, gestation weight gain, and aluminium in mother blood loaded strongly on component 2 . For component 3, maternal age, maternal height, adequate sleep and manganese in the mother blood loaded strongly on components. The maternal variables retained on each component were used as independent variables in developing regression equations that were related to some baby variables measured.

\section{FACTOR LOADINGS VARIMAX ROTATION}

The maternal variables loaded on a component with the factor loading score greater than 0.4 loading factor were used for the regression modelling. Due to large maternal variables available for modelling, only data that are bold and are within component D1, D2 and D3 were used.

\section{MATERNAL VARIABLES AND NEWBORN BODY}

Eight multiple linear regression models were developed relating the baby weight with various mother parameters, and the results are presented in Table 7.

Model 1 was developed relating the baby weight as the dependent variable, and the maternal age, mother body mass index (BMI) and gestation weight gained as the independent variables. The result showed that the predictive power of Model 1 was low due to the low coefficient of determination, $\mathrm{R}^{2}$ and the high Root mean square errors (RMSE). The $\mathrm{R}^{2}$ obtained for Model 1 was just 0.19 , indicating that just $19 \%$ of the variation in the baby weight can be explained by the maternal age, mother BMI and gestation weight gained.

Model 2 related the baby weight with gestation age at delivery, gestation weight and aluminium. It was a better predictive model than Model 1, as the goodness of fit of Model 2 was far better than Model 1 . The $\mathrm{R}^{2}$ obtained for Model 2

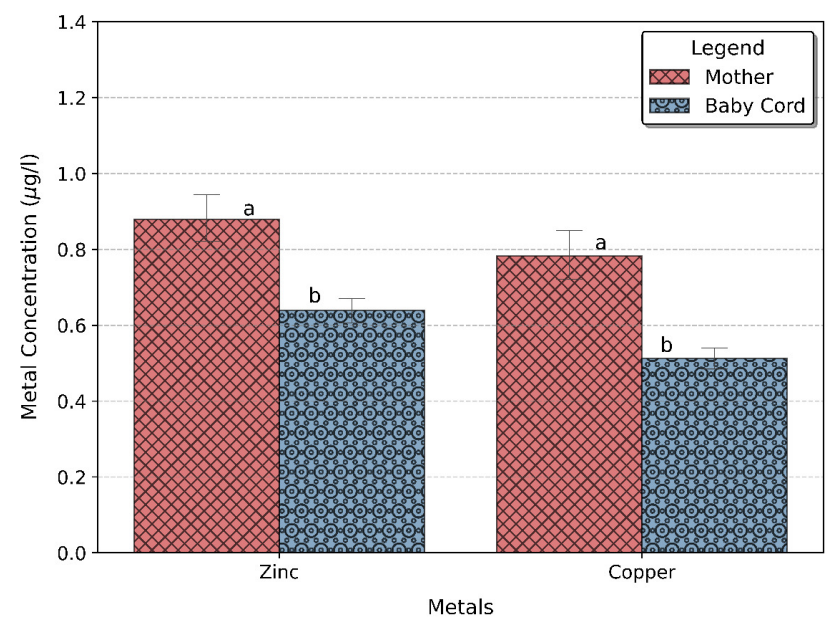

Figure 3. Heavy metals in the mother and baby cord.

was 0.622 , indicating that $62.2 \%$ of the variation in the baby weight can be explained by the independent variables used for Model 2.

Model 3 was developed relating the maternal height, maternal age and manganese but the result obtained showed that Model 3 performed the worst out of the eight models. The $\mathrm{R}^{2}$ of Model 3 was 0.0187 and the RMSE was 943.92 . The result obtained from Model 3, showed that the maternal height, maternal age and manganese in the mother blood does not contribute significantly to the weight gained by the baby.

Model 4 performed better than the three previous models. The coefficient of determination of Model 4 was 0.686 and the RMSE was 533.78 . Model 4 , showed that $68.6 \%$ of the variable in the baby weight can be explained by gestation age at delivery, maternal weight and aluminium in the blood of the mother. The three factors contribute the most 
to the weight gained by the baby and can be used as predictor variables to predict the baby weight.

In other to optimize the accuracy of Model 4, a non-linear model (Model 5) including categorical variables was investigated. Power Model 5 was used to fit the baby weight and the independent variable used in Model 4 in other to see if the predictive power of the model can be increased. The result obtained showed that Model 5 (power model) did not increase the predictive power of Model 4; rather, the predictive power was decreased thus indicating that the relationship between the dependent variables and independent variables might possibly be linear in nature. The goodness of fit for Model 5 gave a $\mathrm{R}^{2}$ of 0.645 and a RMSE of 545.36. Result obtained from Model 4 highlighted some observations, which were outliers in the main data set. It was noted that observation 40 had a baby that was excessive overweight with a baby weight of $4200 \mathrm{~g}$ and observation 48 and 55 had babies that were excessive underweight with baby weight of $600 \mathrm{~g}$ respectively. Inclusion of these observations in Model 4 resulted to the increase in the error associated with the model.

Model 6 was developed using the same independents variables used in Model 4 but without the outliers. The result showed an improvement in the goodness of fit of the model than what was obtained in Model 4 . The $\mathrm{R}^{2}$ value of Model 6 was 0.742 , i.e. improved $8 \%$ with respect to what was obtained in Model 4.

Further models including categorical variables were therefore added as independent variables to those already identified in order to check whether the predictive power of the model for baby weight can be increased.

Model 7 included the quality of mother sleep during pregnancy. Result showed that there was improvement in the predictive power of the model. The $\mathrm{R}^{2}$ value for Model 7 was 0.728 with a RMSE of 501.69 .

Model 8 was developed using Model 7 independents variables but excluding the outliers already identified. Model 8 gave the best predictive power for baby weight, with $\mathrm{R}^{2}$ of 0.76 ; this means that $76 \%$ of the variation in the baby weight can be explained with independent variables used in Model 8. This result indicates that sleeping pattern, gestation age at delivery, aluminium and maternal weight contribute to the baby weight gain.

Model 9 was developed incorporating an interaction term between the maternal weight and aluminium in the mother blood. Model 9 was the best due to it having the highest $\mathrm{R}^{2}$ and lowest RMSE. About $78 \%$ of the variation in the baby weight can be explained by variation in the maternal weight, gestation age, aluminium in mother blood and if the mothers had adequate sleep.

Five additional models were developed therefore, relating the baby length (instead of baby weight) with the various mother parameters as above.

Model 1 showed that obtaining accurate prediction of the baby length will not be possible as the goodness of fit of the model was poor. The coefficient of determination $\mathrm{R}^{2}$ was 0.109 , indicating that just $11 \%$ of the variation in the baby length can be explained by the independent variables used in developing the model. The root mean square error (RMSE) for Model 1 was 6.724 and a mean square error (MSE) of 45.216.

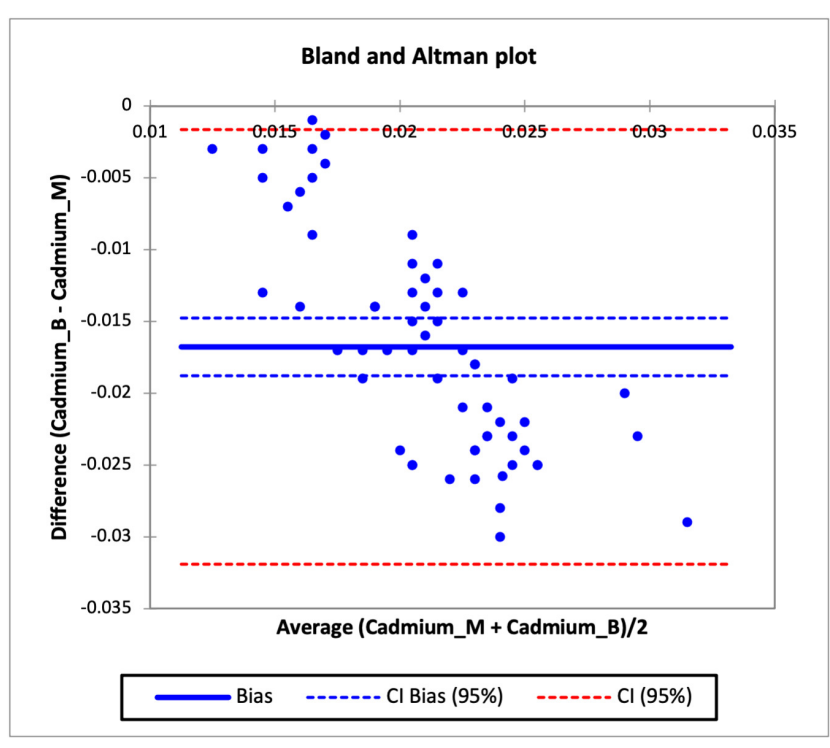

Figure 4. Bland and Altman plot of agreement between the cadmium conc. in mother blood and baby cord

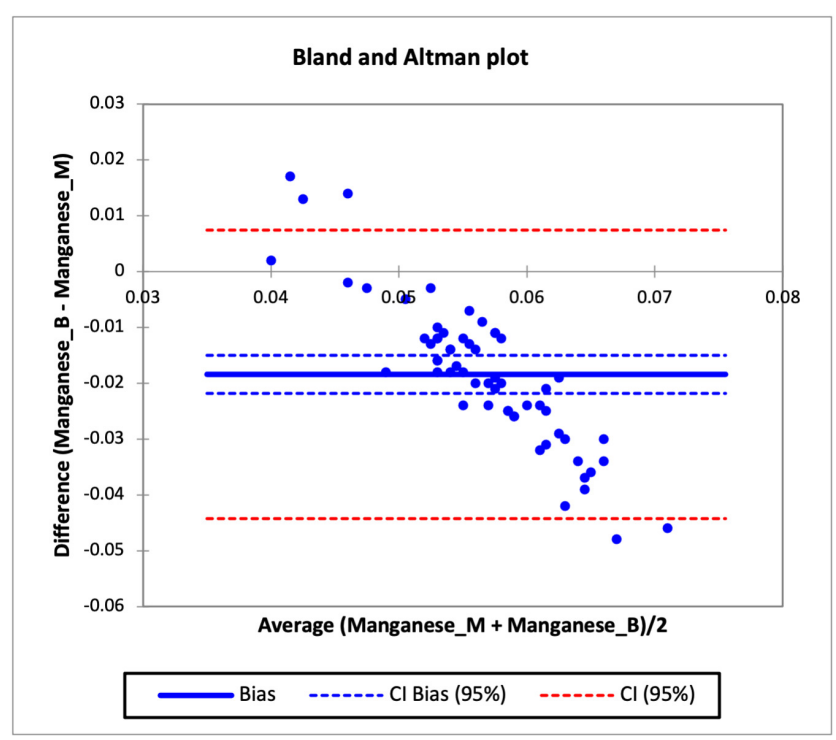

Figure 5. Bland and Altman plot of agreement between the manganese conc. in mother blood and baby cord

Model 2 developed relating the baby length as the dependent variable with gestation age at delivery, gestation weight gained and aluminium gave a much better model than Model 1 . The $\mathrm{R}^{2}$ value was 0.556 , indicating that $56 \%$ of the variation in the baby weight can be explained by the independent variables used in Model 2.

Model 3 developed performed the worst with very low goodness of fit.

Model 4 related the baby length and gestation age at delivery, aluminium and maternal weight. The result showed significantly improvement compared to the previous three models. The coefficient of determination for Model 3 was 0.573 and the RMSE was 4.61 . 
It was observed from Pearson correlation (Table 5) that the baby weight is strongly correlated with baby length. The baby weight was used as an independent variable in addition with the other independent variables used in Model 4. The result showed significant improvement in the predictive power for the baby length. The coefficient of determination was 0.622 and the RMSE was 4.38. The result showed that the baby length could be predicted to a good degree with Model 5, and gestation age at delivery, aluminium, maternal weight and baby weight strong contribute to the baby length.

Model 6 relating the baby length and other independent variables was the best. The coefficient of determination obtained for model 6 was 0.668 , which indicate that about $67 \%$ of the variation in the baby length can be explained by the gestation age, maternal weight, aluminium in mother blood and if the mother had adequate sleep.

\section{DISCUSSION}

In this study, the higher metal (Aluminium, Cadmium, Copper, Lead, Manganese, Zinc) levels found in maternal blood than cord blood corroborate with earlier studies that reported how most neonatal metal exposures occur in response to maternal exposure and often occur during nutrient supply and exchange between the mother and the fetus. ${ }^{4,6,16}$ This also has far reaching implications on the need for public health practice and behavioural adjustments during pregnancy as often time occupational hazard exposures and consumption practices are the major route of maternal metal exposure during pregnancy. ${ }^{4,6,7,17}$

The observation that Zinc concentration is the most predominant in the maternal blood and cord blood is not surprising owing to the metabolic significance of zinc in development. Zinc metal has been implicated to function as an essential element and works in tandem with several other nutrient factors in growth maintenance and the modulation of the immune system and mental development. ${ }^{18-20}$ Also, maternal and cord blood copper being the second most predominant metal in this study is not also far from the metabolic significance of copper as an essential micronutrient because its deficiency has been implicated and linked to congenital birth disorders, induced maternal hypertension, premature birth and still birth, placental abruption and low birth weight. ${ }^{21-23}$ Findings in this study did not vary from reports that exist in literature. Maternal blood Aluminium concentration had the highest significant negative correlation with baby body weight $(-0.6081)$ and birth length $(-0.6107)$. On the overall, Aluminium, Cadmium, Copper, and Zinc contributed significantly to low-birth-weight outcomes in offspring outcomes. The implication of these observations is that although metals such as Cadmium, Copper and Zinc may not have had direct influence on the baby length and baby weight individually, an interaction between their impacts on other morphometric factors such as head circumference, birth length and birth weight must have influenced the general weight outcomes. This finding is in tandem with the study of Emokpae et $\mathrm{al}^{24}$ which reported that maternal Cadmium levels significantly correlated negatively with baby weight and low birth weight outcomes in Benin city South western Nigeria and with the study of

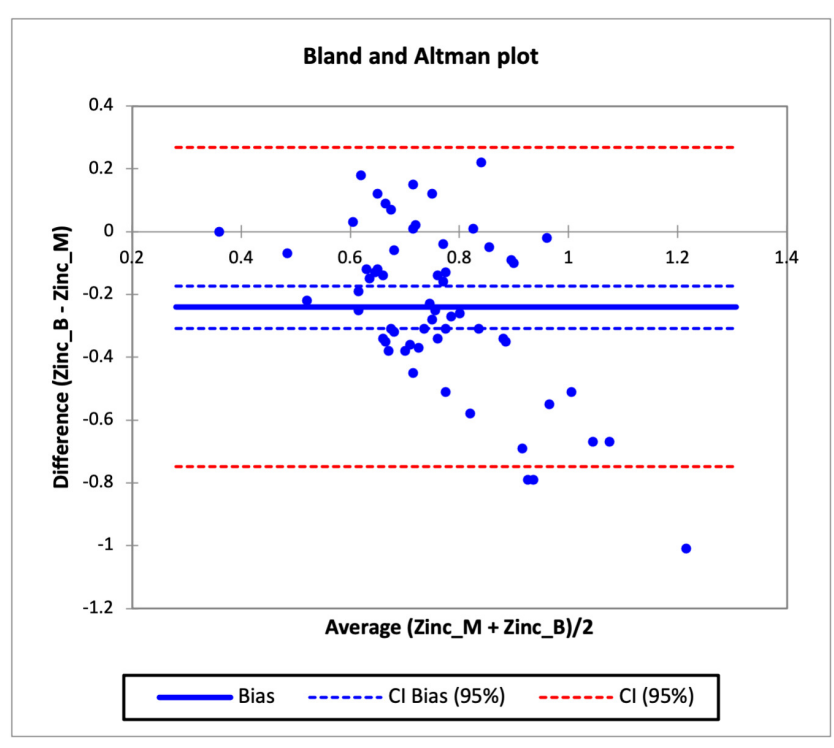

Figure 6. Bland and Altman plot of agreement between the zinc conc. in mother blood and baby cord

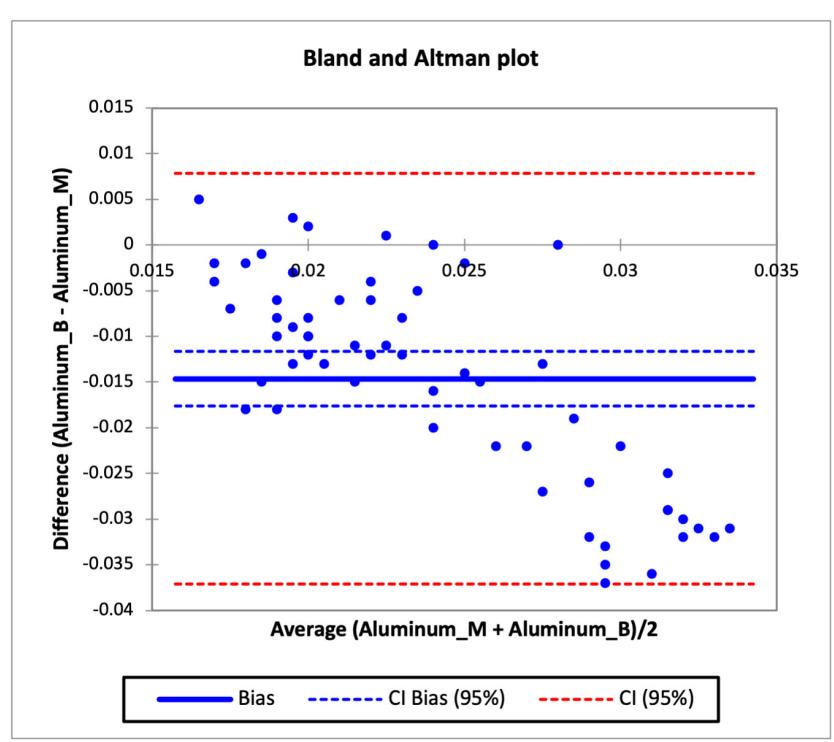

Figure 7. Bland and Altman plot of agreement between the aluminum conc. in mother blood and baby cord

Johnson et al. (2014) in North Carolina. The observed negative correlation for zinc however does not agree with Emokpae et al. ${ }^{24}$ as maternal blood Zinc concentrations positively correlated with baby weight outcomes implying that it contributed to weight gains. Another significant explanation of the ability of cadmium to negatively influence low birth weight outcomes is related to the mechanism behind its transportation as it has the ability to be easily bound and transported by the metallothionein thereby increasingly displacing the Zinc cofactor in heam. Once this is done, Zinc transportation which is an essential element for metabolic stability is distorted which in turn affects the functional role of zinc as a growth factor. ${ }^{25,26}$ On the other 
Table 3c. Percentage reduction in metal concentration in mother blood and baby cord blood

\begin{tabular}{ccccccc}
\hline & Aluminum & Cadmium & Copper & Manganese & Zinc \\
\hline bias & -0.0146 & -0.0168 & -0.2703 & -0.0184 & -0.2407 \\
Cl of Bias & $(-0.018,-0.012)$ & $(-0.019,-0.015)$ & $(-0.341,-0.120)$ & $(-0.022,-0.015)$ & $(-0.308,-0.174)$ \\
Limit of Agreement & $(-0.037,0.008)$ & $(-0.032,-0.002)$ & $(-0.806,-0.266)$ & $(-0.044,0.008)$ & $(-0.749,0.268)$ \\
\hline
\end{tabular}

hand, the reported significant negative correlation of copper to low-birth-weight outcomes is similar to the reasons given for zinc as it has been reported that copper also acts as a cofactor to several antioxidants which fights against oxidative radicals capable of inducing inflammatory responses that might affect weight negatively. ${ }^{27-29}$ Indeed, altered homeostasis of essential elements can impact on newborn body size. ${ }^{4}$

In another development, the non-significant correlation of manganese to outcomes of baby size may be explained and linked to the essentiality of manganese which may imply that the metal levels in the mother and the baby is at a level where it is readily absorbed for proper body functioning. On the other hand, the negative correlation between Lead and baby length may implicate lead in affecting baby growth as previously postulated but however may be acting not as a front liner in affecting baby size. As earlier stated, aluminium is said to have the highest contribution of impeding baby size with an $\mathrm{R}^{2}$ value of 0.369 and 0.376 in the linear and quadratic models of prediction of factors affected. Although Aluminium toxicity has been established to induce several levels of neurodegeneration, pregnant women have linked its route of exposure in prenatal conditions to drug administrations in form of injections and continual consumption of antacids. Likewise, pregnant women continually consuming citrate containing beverages are said to significantly increase their ability to absorb aluminium from the gut which is eventually passed on to their babies. ${ }^{11,17}$ The high $\mathrm{R}^{2}$ value implicative of the fact that aluminium contributed to about $37 \%$ and also agrees on the ability of aluminium to significantly impact birth weight outcomes negatively. ${ }^{11}$ Another dimension to the observation concerning aluminium is the dependability of Aluminium status on the concentrations of essential elements like Copper, Manganese, Selenium, Zinc, that are essential for several enzymatic functionalities. ${ }^{26,30,31}$ Putting all size factors (birth weight, baby length, and low birth weight and head circumference) into consideration, however, there were also significant positive correlation between birth weight and BMI. The implication of this observation is that the BMI (a function of maternal weight and height) positively affects the baby weight. This trend is in consonance with conclusions established in various researches in literature that low BMI mothers tend to have premature babies while high BMI mothers are prone to giving birth to over weight babies; an indication that this factor should be closely monitored throughout pregnancy. ${ }^{32,33}$ Also, the positive correlation between maternal BMI and baby body weight is in agreement with findings at the antenatal at-

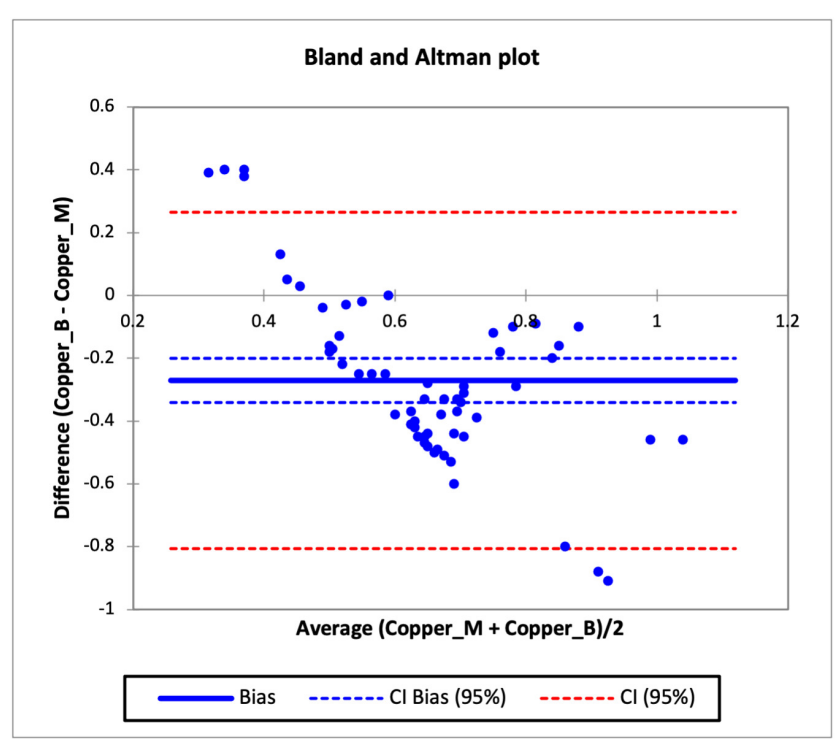

Figure 8. Bland and Altman plot of agreement between the copper conc. in mother blood and baby cord

tendees at Usman Danfodio University Teaching Hospital UDUTH,Sokoto, Nigeria. ${ }^{18}$ Several factors have been alluded to influence underweight birth outcomes which includes parity, maternal health status, short birth spacing, nutritional factors, socioeconomic factors, quality and quantity of antenatal care as well as maternal age. ${ }^{34}$ All of these factors are modifiable hence it is of paramount importance to increase awareness campaigns on safe pregnancy, nutrition and quality care during pregnancy.

Following the principal component analysis, the regression model for the factors that best predicts the baby weight and baby length were carried out. Outcomes from the analysis revealed that the best model that predicted the baby weight was the model 8 having a predictive power for baby weight with $\mathrm{R}^{2}$ of 0.76 implying $76 \%$ of the variation in the baby weight can be explained by the sleeping pattern, gestation age at delivery, aluminium and maternal weight. This finding further gives credence to our earlier submissions on the role of maternal blood Aluminium concentrations on baby weight. Likewise, the reported positive coefficients in the model for maternal weight give credence to our earlier submission on maternal BMI since it remains a function of the maternal weight and height. ${ }^{35}$ 
Table 4. Pearson Correlation showing the relationship between maternal (m) and cord blood (c) metal level

\begin{tabular}{|c|c|c|c|c|c|c|c|c|c|c|}
\hline Variables & Cadmium_M & Manganese_M & Zinc_M & Aluminum_M & Copper_M & Cadmium_B & Manganese_B & Zinc_B & Aluminum_B & Copper_B \\
\hline Cadmium_M & 1.00 & & & & & & & & & \\
\hline Manganese_M & 0.09 & 1.00 & & & & & & & & \\
\hline Zinc_M & 0.27 & 0.01 & 1.00 & & & & & & & \\
\hline Aluminum_M & 0.35 & -0.03 & 0.32 & 1.00 & & & & & & \\
\hline Copper_M & -0.04 & 0.01 & 0.12 & 0.21 & 1.00 & & & & & \\
\hline Cadmium_B & -0.01 & 0.02 & 0.24 & 0.22 & -0.07 & 1.00 & & & & \\
\hline Manganese_B & -0.25 & -0.12 & 0.31 & -0.18 & -0.03 & 0.33 & 1.00 & & & \\
\hline Zinc_B & -0.33 & -0.11 & 0.14 & -0.29 & 0.11 & 0.07 & 0.38 & 1.00 & & \\
\hline Aluminum_B & -0.26 & -0.18 & -0.06 & -0.22 & -0.15 & 0.00 & 0.12 & -0.03 & 1.00 & \\
\hline Copper_B & 0.33 & 0.02 & -0.01 & 0.51 & 0.15 & -0.05 & 0.01 & -0.38 & -0.21 & 1.00 \\
\hline
\end{tabular}

Values in bold are different from 0 with a significance level alpha $=0.05$

Table 5. Pearson Correlation showing the relationship between maternal blood $(\mathrm{m})$ metal level and baby body size.

\begin{tabular}{|c|c|c|c|c|c|c|c|c|c|c|}
\hline Variables & $\begin{array}{l}\text { Low birth } \\
\text { weight }\end{array}$ & $\begin{array}{c}\text { Head } \\
\text { circumference }\end{array}$ & $\begin{array}{l}\text { Baby Weight } \\
\text { (g) }\end{array}$ & $\begin{array}{l}\text { Birth } \\
\text { length }\end{array}$ & Lead_m & Cadmium_m & Manganese_m & Zinc_m & Aluminum_m & Copper_m \\
\hline Low birth weight & 1 & 0.1324 & 0.1831 & 0.2568 & -0.0496 & -0.2997 & 0.0646 & -0.3442 & -0.3628 & 0.3407 \\
\hline $\begin{array}{c}\text { Head } \\
\text { circumference }\end{array}$ & 0.1324 & 1 & 0.2428 & 0.2776 & -0.0984 & 0.0011 & 0.1480 & 0.0072 & -0.1977 & 0.1513 \\
\hline Baby Weight (g) & 0.1831 & 0.2428 & 1 & 0.7467 & -0.1646 & -0.0843 & 0.0018 & -0.1836 & -0.6081 & -0.0499 \\
\hline Birth length & 0.2568 & 0.2776 & 0.7467 & 1 & -0.2689 & -0.2047 & -0.1047 & -0.2048 & -0.6107 & 0.1425 \\
\hline Lead_m & -0.0496 & -0.0984 & -0.1646 & -0.2689 & 1 & 0.2167 & 0.2766 & -0.2452 & 0.1833 & -0.2535 \\
\hline Cadmium_m & -0.2997 & 0.0011 & -0.0843 & -0.2047 & 0.2167 & 1 & 0.0901 & 0.2684 & 0.3525 & -0.0377 \\
\hline Manganese_m & 0.0646 & 0.1480 & 0.0018 & -0.1047 & 0.2766 & 0.0901 & 1 & 0.0055 & -0.0295 & 0.0119 \\
\hline Zinc_m & -0.3442 & 0.0072 & -0.1836 & -0.2048 & -0.2452 & 0.2684 & 0.0055 & 1 & 0.3191 & 0.1179 \\
\hline Aluminum_m & -0.3628 & -0.1977 & -0.6081 & -0.6107 & 0.1833 & 0.3525 & -0.0295 & 0.3191 & 1 & 0.2116 \\
\hline Copper_m & 0.3407 & 0.1513 & -0.0499 & 0.1425 & -0.2535 & -0.0377 & 0.0119 & 0.1179 & 0.2116 & 1 \\
\hline
\end{tabular}

Values in bold are different from 0 with a significance level alpha $=0.05$ 
Table 6. Eigen-value result.

\begin{tabular}{|c|c|c|c|c|c|c|c|c|c|c|}
\hline & F1 & F2 & F3 & F4 & F5 & F6 & F7 & F8 & F9 & F10 \\
\hline Eigen & 2.695 & 2.265 & 1.657 & 1.417 & 1.103 & 1.006 & 0.942 & 0.863 & 0.726 & 0.447 \\
\hline Variability & 19.249 & 16.178 & 11.837 & 10.118 & 7.880 & 7.183 & 6.727 & 6.163 & 5.185 & 3.195 \\
\hline Cumula. \% & 19.249 & 35.427 & 47.264 & 57.382 & 65.261 & 72.444 & 79.171 & 85.334 & 90.519 & 93.714 \\
\hline
\end{tabular}

Table 7. Factor loadings after varimax rotation.

\begin{tabular}{|c|c|c|c|c|c|c|}
\hline Variables & $\mathrm{D} 1$ & D2 & D3 & D4 & D5 & D6 \\
\hline Maternal age & 0.42 & 0.1152 & 0.5914 & -0.2057 & 0.3409 & -0.0627 \\
\hline Maternal height & 0.0482 & -0.1769 & 0.5279 & -0.0964 & -0.3921 & 0.3958 \\
\hline Maternal weight & 0.8397 & -0.1212 & 0.3196 & -0.106 & -0.2206 & 0.1387 \\
\hline Mother BMI & 0.9004 & -0.0228 & -0.0312 & -0.0332 & 0.0378 & -0.1258 \\
\hline Low birth weight & 0.0164 & -0.357 & 0.022 & 0.616 & 0.0449 & -0.3736 \\
\hline Gestation age at delivery & -0.0368 & -0.9213 & 0.0217 & 0.086 & -0.0306 & -0.0272 \\
\hline Gestation weight gain & 0.4749 & 0.4537 & -0.2021 & 0.0277 & 0.334 & -0.003 \\
\hline Lead & -0.3742 & 0.2479 & -0.1592 & -0.447 & -0.2526 & -0.4692 \\
\hline Cadmium & -0.1444 & 0.3027 & -0.1433 & -0.2415 & -0.3309 & 0.3156 \\
\hline Manganese & -0.0889 & -0.0352 & -0.8104 & -0.0993 & -0.0315 & 0.0335 \\
\hline Zinc & -0.0436 & 0.1764 & -0.0176 & 0.0342 & 0.0053 & 0.8858 \\
\hline Aluminium & -0.3204 & 0.7345 & 0.1229 & 0.1062 & -0.272 & 0.2397 \\
\hline Adequate sleep & -0.1546 & 0.0814 & -0.4303 & 0.8885 & -0.0529 & 0.1087 \\
\hline
\end{tabular}


Table 8. Summary table for various Models developed relating the baby weight with some mother variables.

\begin{tabular}{|c|c|c|c|c|}
\hline $\mathrm{S} / \mathrm{N}$ & Model & Model Parameters & Goodness of Fit & Remark \\
\hline 1 & $\begin{array}{l}y=a_{0}+a_{1} x_{1}+a_{2} x_{2}+a_{3} x_{3}+a_{4} x_{4} \\
\text { where } x_{1}=\text { maternal age } \\
x_{2}=\text { maternal weight } \\
x_{3}=\text { mother BMI } \\
x_{4}=\text { gestation weight gain }\end{array}$ & $\begin{array}{l}a_{0}=291.06 \\
a_{1}=-6.48 \\
a_{2}=21.63 \\
a_{3}=26.63 \\
a_{4}=-17.36\end{array}$ & $\begin{array}{l}R^{2}=0.191 \\
\text { Adj. } R^{2}=0.132 \\
M S E=747820 \\
\text { RMSE }=864.76\end{array}$ & Bad \\
\hline 2 & $\begin{array}{l}y=a_{0}+a_{1} x_{1}+a_{2} x_{2}+a_{3} x_{3} \\
\text { where } x_{1}=\text { gestation age at delivery } \\
x_{2}=\text { gestation weight gain } \\
x_{3}=\text { Aluminium }\end{array}$ & $\begin{array}{l}a_{0}=-1526.14 \\
a_{1}=128.74 \\
a_{2}=1.88 \\
a_{3}=-21193.42\end{array}$ & $\begin{array}{l}R^{2}=0.622 \\
\text { Adj. } R^{2}=0.602 \\
M S E=343380 \\
\text { RMSE }=585.98\end{array}$ & Fair \\
\hline 3 & $\begin{array}{l}y=a_{0}+a_{1} x_{1}+a_{2} x_{2}+a_{3} x_{3} \\
\text { where } x_{1}=\text { maternal age } \\
x_{2}=\text { maternal height } \\
x_{3}=\text { Manganese }\end{array}$ & $\begin{array}{l}a_{0}=-163.28 \\
a_{1}=11.99 \\
a_{2}=1260.33 \\
a_{3}=3306.14\end{array}$ & $\begin{array}{l}R^{2}=0.0187 \\
\text { Adj. } R^{2}=-0.03 \\
M S E=890974 \\
\text { RMSE }=943.92\end{array}$ & Bad \\
\hline 4 & $\begin{array}{l}y=a_{0}+a_{1} x_{1}+a_{2} x_{2}+a_{3} x_{3} \\
\text { where } x_{1}=\text { maternal weight } \\
x_{2}=\text { gestation age at delivery } \\
x_{3}=\text { Aluminium }\end{array}$ & $\begin{array}{l}a_{0}=-3068.68 \\
a_{1}=19.03 \\
a_{2}=127.60 \\
a_{3}=-17484.1\end{array}$ & $\begin{array}{l}R^{2}=0.686 \\
\text { Adj. } R^{2}=0.670 \\
M S E=284917 \\
R M S E=533.78\end{array}$ & Good \\
\hline 5 & $\begin{array}{l}y=a_{0} x_{1} a_{1 x_{2}} a_{2 x_{3}} a_{3} \\
\text { where } x_{1}=\text { maternal weight } \\
x_{2}=\text { gestation age at delivery } \\
x_{3}=\text { Aluminium }\end{array}$ & $\begin{array}{l}a_{0}=0.105 \\
a_{1}=0.499 \\
a_{2}=2.0383 \\
a_{3}=-0.158\end{array}$ & $\begin{array}{l}\mathrm{R}^{2}=0.645 \\
M S E=297419 \\
\mathrm{RMSE}=545.36\end{array}$ & Fair \\
\hline 6 & $\begin{array}{l}y=a_{0}+a_{1} x_{1}+a_{2} x_{2}+a_{3} x_{3} \\
\text { outliers were removed } \\
\text { where } x_{1}=\text { gestation age at delivery } \\
x_{2}=\text { Aluminium } \\
x_{3}=\text { maternal weight }\end{array}$ & $\begin{array}{l}a_{0}=-1978.77 \\
a_{1}=127.72 \\
a_{2}=-18508.15 \\
a_{3}=5.565\end{array}$ & $\begin{array}{l}R^{2}=0.742 \\
\text { Adj. } R^{2}=0.727 \\
M S E=199692 \\
\text { RMSE }=446.87\end{array}$ & Good \\
\hline 7 & $\begin{array}{l}y=a_{0}+a_{1} x_{1}+a_{2} x_{2}+a_{3} x_{3}+a_{4} x_{4} \\
\text { where } x_{1}=\text { maternal weight } \\
x_{2}=\text { gestation age at delivery } \\
x_{3}=\text { Aluminium } \\
x_{4}=\text { adequate sleep }\end{array}$ & $\begin{array}{l}a_{0}=-3470.95 \\
a_{1}=19.625 \\
a_{2}=126.47 \\
a_{3}=-11165.64 \\
a_{4}=397.91\end{array}$ & $\begin{array}{l}R^{2}=0.728 \\
\text { Adj. } R^{2}=0.708 \\
M S E=251692 \\
R M S E=501.69\end{array}$ & Good \\
\hline 8 & $\begin{array}{l}y=a_{0}+a_{1} x_{1}+a_{2} x_{2}+a_{3} x_{3}+a_{4} x_{4} \\
\text { where } x_{1}=\text { gestation age at delivery } \\
x_{2}=\text { Aluminium } \\
x_{3}=\text { maternal weight } \\
x_{4}=\text { adequate sleep } \\
\text { where } x_{4} \text { equal; } 1=\text { No and } 0=\text { Yes }\end{array}$ & $\begin{array}{l}a_{0}=-2427 \\
a_{1}=127.90 \\
a_{2}=-13580 \\
a_{3}=7.678 \\
a_{4}=250.05\end{array}$ & $\begin{array}{l}R^{2}=0.7601 \\
\text { Adj. } R^{2}=0.742 \\
M S E=188861 \\
\text { RMSE }=438.58\end{array}$ & Good \\
\hline 9 & $\begin{array}{l}y=a_{0}+a_{1} x_{1}+a_{2} x_{2}+a_{3} x_{3}+a_{4} x_{4}+a_{5} x_{2} x_{3} \\
\text { where } x_{1}=\text { gestation age at delivery } \\
x_{2}=\text { Aluminium } \\
x_{3}=\text { maternal weight } \\
x_{4}=\text { adequate sleep } \\
\text { where } x_{4} \text { equal; } 1=\text { No and } 0=\text { Yes }\end{array}$ & $\begin{array}{l}a_{0}=-300.91 \\
a_{1}=-21.614 \\
a_{2}=129.81 \\
a_{3}=-89479.99 \\
a_{4}=289.03 \\
a_{5}=1013.97\end{array}$ & $\begin{array}{l}\mathrm{R}^{2}=0.775 \\
\text { Adj. } \mathrm{R}^{2}=0.753 \\
\mathrm{MSE}=180311 \\
\mathrm{RMSE}=424.87\end{array}$ & $\begin{array}{l}\text { Good } \\
\text { (Best) }\end{array}$ \\
\hline
\end{tabular}

Relative to the model for the prediction of baby length, model 5 revealed that the coefficient of determination was 0.622 and the RMSE was 4.38 . The result from development of the models showed that the baby length can be predicted to a good degree with model 5 , and gestation age at delivery, aluminium, maternal weight and baby weight strongly contributes to the baby length. The factors listed above could be observed to have been included in the predictability of the body weight except for baby weight which was included in the model.

The limited population size is obvious limitation of this study. Furthermore, this is cross sectional study; causal relationships cannot be confirmed in the pathophysiological mechanism to link the blood metal with anthropometry, secondly study was based in one ethnic group and may not be generalised to other ethnicities and finally only blood metal especially lead levels which reflect only recent exposure.

\section{CONCLUSIONS}

Many of the determinants of birth weight are related to maternal suboptimal nutrition and infants' deficiency of some essential trace elements, and also to maternal environmental exposures to toxic pollutants. Elaboration of policies aimed at promoting safer foods and environment, healthy dietary habits and lifestyles as well as reducing the health impact of chronic diseases needs to pay special attention to the pre- and periconceptional period. Further elucidation of the links between environmental exposures and birth outcomes must come through linking biomarkers and surveillance approaches, including monitoring improvements in 
Table 9. Summary table for various Models developed relating the baby length with some mother variables

\begin{tabular}{|c|c|c|c|c|}
\hline $\mathrm{S} / \mathrm{N}$ & Model & Model Parameters & Goodness of Fit & Remark \\
\hline 1 & $\begin{array}{l}y=a_{0}+a_{1} x_{1}+a_{2} x_{2}+a_{3} x_{3}+a_{4} x_{4} \\
\text { where } x_{1}=\text { maternal age } \\
x_{2}=\text { maternal weight } \\
x_{3}=\text { mother BMI } \\
x_{4}=\text { gestation weight gain }\end{array}$ & $\begin{array}{l}a_{0}=27.79 \\
a_{1}=0.147 \\
a_{2}=0.118 \\
a_{3}=0.091 \\
a_{4}=-0.048\end{array}$ & $\begin{array}{l}\mathrm{R}^{2}=0.109 \\
\text { Adj. } \mathrm{R}^{2}=0.044 \\
\mathrm{MSE}=45.216 \\
\mathrm{RMSE}=6.724\end{array}$ & Bad \\
\hline 2 & $\begin{array}{l}y=a_{0}+a_{1} x_{1}+a_{2} x_{2}+a_{3} x_{3} \\
\text { where } x_{1}=\text { gestation age at delivery } \\
x_{2}=\text { gestation weight gain } \\
x_{3}=\text { Aluminium }\end{array}$ & $\begin{array}{l}a_{0}=15.612 \\
a_{1}=0.912 \\
a_{2}=0.092 \\
a_{3}=-166.76\end{array}$ & $\begin{array}{l}\mathrm{R}^{2}=0.556 \\
\text { Adj. } \mathrm{R}^{2}=0.533 \\
\mathrm{MSE}=22.09 \\
\text { RMSE }=4.70\end{array}$ & Fair \\
\hline 3 & $\begin{array}{l}\mathrm{y}=a_{0}+a_{1} x_{1}+a_{2} x_{2}+a_{3} x_{3} \\
\text { where } x_{1}=\text { maternal age } \\
x_{2}=\text { maternal height } \\
x_{3}=\text { Manganese }\end{array}$ & $\begin{array}{l}a_{0}=27.32 \\
a_{1}=0.235 \\
a_{2}=6.497 \\
a_{3}=-15.06\end{array}$ & $\begin{array}{l}\mathrm{R}^{2}=0.053 \\
\text { Adj. } \mathrm{R}^{2}=0.002 \\
\mathrm{MSE}=47.20 \\
\mathrm{RMSE}=6.870\end{array}$ & Bad \\
\hline 4 & $\begin{array}{l}y=a_{0}+a_{1} x_{1}+a_{2} x_{2}+a_{3} x_{3} \\
\text { where } x_{1}=\text { maternal weight } \\
x_{2}=\text { gestation age at delivery } \\
x_{3}=\text { Aluminium }\end{array}$ & $\begin{array}{l}a_{0}=14.05 \\
a_{1}=0.118 \\
a_{2}=0.7420 \\
a_{3}=-190.06\end{array}$ & $\begin{array}{l}\mathrm{R}^{2}=0.573 \\
\text { Adj. } \mathrm{R}^{2}=0.550 \\
\mathrm{MSE}=21.28 \\
\text { RMSE }=4.61\end{array}$ & Fair \\
\hline 5 & $\begin{array}{l}y=a_{0}+a_{1} x_{1}+a_{2} x_{2}+a_{3} x_{3} \\
\text { where } x_{1}=\text { maternal weight } \\
x_{2}=\text { gestation age at delivery } \\
x_{3}=\text { Aluminium } \\
x_{4}=\text { baby weight }\end{array}$ & $\begin{array}{l}a_{0}=23.019 \\
a_{1}=0.063 \\
a_{2}=0.369 \\
a_{3}=-138.96 \\
a_{3}=0.0029\end{array}$ & $\begin{array}{l}\mathrm{R}^{2}=0.622 \\
\text { Adj. } \mathrm{R}^{2}=0.594 \\
\mathrm{MSE}=19.19 \\
\mathrm{RMSE}=4.38\end{array}$ & Good \\
\hline 6 & $\begin{array}{l}y=a_{0}+a_{1} x_{1}+a_{2} x_{2}+a_{3} x_{3}+a_{4} x_{4} \\
\text { where } x_{1}=\text { maternal weight } \\
x_{2}=\text { gestation age at delivery } \\
x_{3}=\text { Aluminium } \\
x_{4}=\text { adequate sleep } \\
\text { where } x_{4} \text { equal; } 1=\text { No and } 0=\text { Yes }\end{array}$ & $\begin{array}{l}a_{0}=18.6473 \\
a_{1}=0.1498 \\
a_{2}=0.521 \\
a_{3}=-190.99 \\
a_{4}=2.519\end{array}$ & $\begin{array}{l}\mathrm{R}^{2}=0.668 \\
\text { Adj. } \mathrm{R}^{2}=0.643 \\
\mathrm{MSE}=13.60 \\
\mathrm{RMSE}=3.68\end{array}$ & $\begin{array}{l}\text { Good } \\
\text { (Best) }\end{array}$ \\
\hline
\end{tabular}

preconception health.

\section{ACKNOWLEDGMENTS}

This study was partly funded under the project "Lifestyle and environment and transgenerational health in Nigeria" granted by the University of Tuscia, Viterbo, Italy, to the pan African NGO NOODLES (Nutrition \& food safety and wholesomeness - Prevention, education and research, www.noodlesonlus.org) (2017-2019).

\section{FUNDING}

None

\section{AUTHORSHIP CONTRIBUTIONS}

All co-authors contributed to study design and writing of manuscript.

\section{COMPETING INTERESTS}

The authors completed the Unified Competing Interest form at http://www.icmje.org/disclosure-of-interest/ (available upon request from the corresponding author) and declare no conflicts of interest.

\section{CORRESPONDENCE TO:}

Orish Ebere Orisakwe, World Bank Africa Centre of Excellence in Public Health and Toxicological Research (PUTOR), University of Port Harcourt, PMB, 5323 Port Harcourt, Rivers State, Nigeria.

orishebere@gmail.com; orish.orisakwe@uniport.edu.ng

Submitted: September 23, 2021 GMT, Accepted: October 25, 2021 GMT

This is an open-access article distributed under the terms of the Creative Commons Attribution 4.0 International License (CCBY-4.0). View this license's legal deed at http://creativecommons.org/licenses/by/4.0 and legal code at http://creativecommons.org/licenses/by/4.0/legalcode for more information. 


\section{REFERENCES}

1. Sanders T, Liu Y, Buchner V, Tchounwou PB. Neurotoxic effects and biomarkers of lead exposure: A review. Rev Environ Health. 2009;24(1):15-45. doi:10.1 515/reveh.2009.24.1.15

2. Takai I, Audu B, Bukar M. A prospective study of maternal risk factors for low birth weight babies in Maiduguri, North-Eastern Nigeria. Niger J Basic Clin Sci. 2014;11(2):89. doi:10.4103/0331-8540.140353

3. Rauh VA, Margolis AE. Research Review: Environmental exposures, neurodevelopment, and child mental health - new paradigms for the study of brain and behavioral effects. J Child Psychol Psychiatry Allied Discip. 2016;57(7):775-793. doi:10.1111/icpp.12 $\underline{537}$

4. Frazzoli C, Mantovani A. Toxicological risk factors in the burden of malnutrition: The case of nutrition (and risk) transition in sub-Saharan Africa. Food Chem Toxicol. 2020;146(June):111789. doi:10.1016/i.fC t.2020.111789

5. Bocca B, Ciccarelli S, Agostino R, Alimonti A. Trace elements, oxidative status and antioxidant capacity as biomarkers in very low birth weight infants. Environ Res. 2017;156(January):705-713. doi:10.1016/ j.envres.2017.04.027

6. Sabra S, Malmqvist E, Saborit A, Gratacós E, Gomez Roig MD. Heavy metals exposure levels and their correlation with different clinical forms of fetal growth restriction. PLOS ONE. 2017;12(10):1-19. doi:1 $\underline{0.1371 / \text { journal.pone. } 0185645}$

7. Tchounwou PB, Yedjou CG, Patlolla AK, Sutton DJ. Molecular, Clinical and Environmental Toxicicology Volume 3: Environmental Toxicology. Vol 101. Springer Basel; 2012. doi:10.1007/978-3-7643-8340-4

8. Gundacker C, Hengstschläger M. The role of the placenta in fetal exposure to heavy metals. Wien Med Wochenschr. 2012;162(9-10):201-206. doi:10.1007/s10 354-012-0074-3

9. Vanes LD, Murray RM, Nosarti C. Adult outcome of preterm birth: Implications for neurodevelopmental theories of psychosis. Schizophr Res. Published online May 2021. doi:10.1016/i.schres.2021.04.007

10. Arbuckle TE, Liang CL, Morisset AS, et al. Maternal and fetal exposure to cadmium, lead, manganese and mercury: The MIREC study. Chemosphere. 2016;163:270-282. doi:10.1016/j.chemo sphere.2016.08.023
11. Röllin HB, Nogueira C, Olutola B, Channa K, Odland J. Prenatal exposure to aluminum and status of selected essential trace elements in rural South African women at delivery. Int J Environ Res Public Health. 2018;15(7):1-16. doi:10.3390/ijerph15071494

12. Demir N, Başaranoğlu M, Huyut Z, et al. The relationship between mother and infant plasma trace element and heavy metal levels and the risk of neural tube defect in infants. J Matern Neonatal Med. 2019;32(9):1433-1440. doi:10.1080/14767058.2017.14 $\underline{08064}$

13. Abass RM, Hamdan HZ, Elhassan EM, Hamdan SZ, Ali NI, Adam I. Zinc and copper levels in low birth weight deliveries in Medani Hospital, Sudan. BMC Res Notes. 2014;7(1):1-5. doi:10.1186/1756-0500-7-386

14. Nriagu J, Burt B, Linder A, Ismail A, Sohn W. Lead levels in blood and saliva in a low-income population of Detroit, Michigan. Int J Hyg Environ Health. 2006;209(2):109-121. doi:10.1016/j.ijheh.2005.11.005

15. Nwaogazie IL. Finite Element Modelling With Emphasis in Water Resources. Published online January 2008.

16. Maggini S, Wenzlaff S, Hornig D. Essential role of vitamin c and zinc in child immunity and health. J Int Med Res. 2010;38(2):386-414. doi:10.1177/147323001 $\underline{003800203}$

17. Ramakrishnan U, Nguyen P, Martorell R. Effects of micronutrients on growth of children under 5 years of age. Am J Clin Nutr. 2009;89(1):191-203. doi:10.3945/ ajcn.2008.26862.Am

18. Livingstone MBE, Black AE. Biomarkers of Nutritional Exposure and Nutritional Status. J Nutr. 2003;133(3):895S-920S. doi:10.1093/jn/133.3.895s

19. Pathak P, Kapil U. Role of trace elements zinc, copper and magnesium during pregnancy and its outcome. Indian J Pediatr. 2004;71(11):1003-1005. do i:10.1007/bf02828116

20. Ugwuja EI, Akubugwo EI, Ibiam UA, Obidoa O. Maternal sociodemographic parameters: Impact on trace element status and pregnancy outcomes in Nigerian women. J Heal Popul Nutr. 2011;29(2):156-162. doi:10.3329/jhpn.v29i2.7858

21. Emokpae MA, Agbonlahor OJ, Ae E. The relationship between maternal blood cadmium, zinc levels and birth weight of babies in nonoccupationally exposed pregnant women in Benin city, Nigeria. J Med Biomed Res. 2016;15(1):55-61. 
22. Rafati-Rahimzadeh M, Rafati-Rahimzadeh M, Kazemi S, Moghadamnia AA. Cadmium toxicity and treatment: An update. Casp J Intern Med.

2017;8(3):135-145. doi:10.22088/cjim.8.3.135

23. Osredkar J. Copper and Zinc, Biological Role and Significance of Copper/Zinc Imbalance. J Clin Toxicol. 2011;s3(01):1-18. doi:10.4172/2161-0495.s3-001

24. Petersen SV, Enghild JJ. Extracellular superoxide dismutase: Structural and functional considerations of a protein shaped by two different disulfide bridge patterns. Biomed Pharmacother. 2005;59(4):175-182. doi:10.1016/i.biopha.2005.03.010

25. Izquierdo Álvarez S, Castañón SG, Ruata MLC, et al. Updating of normal levels of copper, zinc and selenium in serum of pregnant women. J Trace Elem Med Biol. 2007;21(SUPPL. 1):49-52. doi:10.1016/j.jte mb.2007.09.023

26. Johnston JE, Valentiner E, Maxson P, Miranda ML, Fry RC. Maternal cadmium levels during pregnancy associated with lower birth weight in infants in a North Carolina cohort. PLOS ONE. 2014;9(10):e109661. doi:10.1371/journal.pone.01096 $\underline{61}$

27. Singh S, Shehu C, Nnadi D. The relationship between maternal body mass index and the birth weight of neonates in North-West Nigeria. Sahel Med J. 2016;19(4):185. doi:10.4103/1118-8561.196359

28. Reinke CM, Breitkreutz J, Leuenberger $\mathrm{H}$. Aluminium in Over-the-Counter Drugs: Risks Outweigh Benefits? Drug Saf. 2003;26(14):1011-1025. doi:10.2165/00002018-200326140-00003
29. Gernand AD, Schulze KJ, Stewart CP, West KP Jr, Christian P. Micronutrient deficiencies in pregnancy worldwide: Health effects and prevention. Nat Rev Endocrinol. 2016;12(5):274-289. doi:10.1038/nrendo.2 $\underline{016.37}$

30. Cao T, Qu A, Li Z, et al. The relationship between maternal perfluoroalkylated substances exposure and low birth weight of offspring: a systematic review and meta-analysis. Environ Sci Pollut Res. Published online July 9, 2021:1-18. doi:10.1007/s11356-021-150 $\underline{61-4}$

31. Topçu HO, Güzel Aİ, Özgü E, Yıldız Y, Erkaya S, Uygur D. Birth weight for gestational age: A reference study in a tertiary referral hospital in the middle region of Turkey. J Chinese Med Assoc.

2014;77(11):578-582. doi:10.1016/i.jcma.2014.05.013

32. Yu Z, Han S, Zhu J, Sun X, Ji C, Guo X. PrePregnancy Body Mass Index in Relation to Infant Birth Weight and Offspring Overweight/Obesity: A Systematic Review and Meta-Analysis. PLOS ONE. 2013;8(4):e61627. doi:10.1371/journal.pone.0061627

33. Papazian T, Tayeh GA, Sibai D, Hout H, Melki I, Khabbaz LR. Impact of maternal body mass index and gestational weight gain on neonatal outcomes among healthy Middle-Eastern females. PLoS ONE.

2017;12(7):1-13. doi:10.1371/journal.pone.0181255

34. Ferguson KK, McElrath TF, Meeker JD.

Environmental phthalate exposure and preterm birth. JAMA Pediatr. 2014;168(1):61-67. doi:10.1001/jamape diatrics.2013.3699

35. Heslehurst N, Vieira R, Akhter Z, et al. The association between maternal body mass index and child obesity: A systematic review and meta-analysis. PLoS Med. 2019;16(6):1-20. doi:10.1371/journal.pme $\underline{\text { d. } 1002817}$ 